\title{
COMBINED FORWARD-FLVBACK-CONVERTER WITH ONLY TWO DIODES - FUNCTION AND MODELLING
}

A combined forward and flyback converter with a simple two windings transformer, an inductor, an active switch, two diodes and a buffer capacitor is explained. The voltage transfer ratio and the demagnetizing condition are derived. The voltage transfer ratio of the new converter is significantly higher compared to the forward and the flyback converters. The converter is useful for applications where a flyback converter is too small and a forward converter with its complicate transformer is too expensive. By shunting the two diodes by a third one the efficiency can be increased and due to the reduced losses the cooling is easier. The state space equations of the different states of the converter are derived.

\section{Introduction}

The well-known classical forward converter [1, 2, 3, 4, 5] needs three windings. Two are used to transform the energy and the third one is necessary to demagnetize the core. The new combined forward-flyback converter (Fig. 1) needs only two windings [6]. The transformer is therefore easier to manufacture, is smaller, has lower weight and is therefore cheaper. No additional component compared to the classical forward converter is necessary. Some other concepts for forward converters are published $[7,8,9,10,11,12$ and 13].

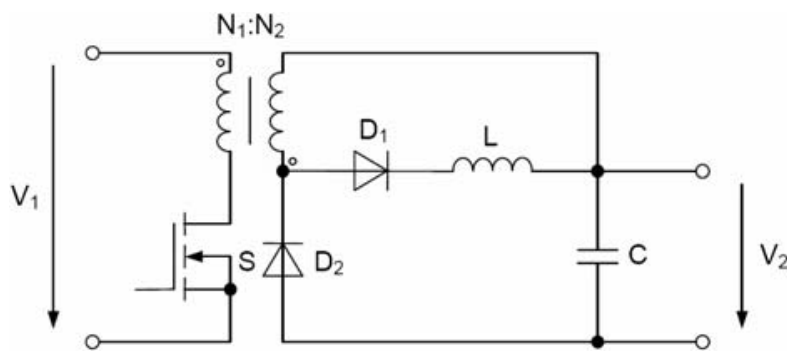

Fig. 1 Circuit of the combined forward-flyback converter

\section{Function}

To explain the principal function, the following assumptions are made: ideal devices, discontinuous inductor current mode (DICM), the circuit is in steady state condition, the output capacitor is so large that the output voltage is constant, and the input of the circuit is fed by a constant voltage source. The switching period can be divided into three states (Fig. 2).

\section{A. State 1}

The circuit diagram of state 1 is shown in Fig 2a. The active switch $S$ is closed. The input voltage is applied to the primary winding $N_{1}$ and the input current rises linearly (dot and dash line). The voltage $\left(N_{2} / N_{1}\right) V_{1}$ is now across the secondary winding $N_{2}$. The secondary current now closes over the diode $D_{1}$, the output inductor $L$, and the secondary winding $N_{2}$ (dotted line). The current rises linearly according to

$$
\frac{d i_{N 2}}{d t}=\frac{N_{2}}{N_{1}} \cdot \frac{V_{1}}{L}
$$

The load is supplied by the capacitor $C$ (long dashed line). The input current consists of two components: the transformed secondary current and the current to magnetize the transformer (primary inductancewhich has $\mathrm{N} 1$ turns)

$$
i_{N 1}=\left[\left(\frac{N_{2}}{N_{1}}\right)^{2} \cdot \frac{V_{1}}{L}+\frac{V_{1}}{L_{1}}\right] \cdot t
$$

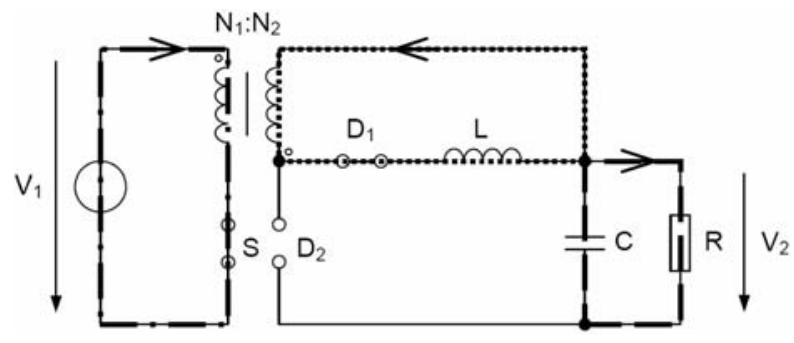

Fig. 2a State 1 of the combined forward-flyback converter

\footnotetext{
* Felix A. Himmelstoss ${ }^{1}$, Helmut L. Votzi ${ }^{2}$

${ }^{1}$ University of Applied Science Technikum, Wien, Austria, E-mail: felix.himmelstoss@technikum-wien.at

${ }^{2}$ University of Technology Vienna, Institute of Electrical Drives and Machines, Wien, Austria
} 
B. State 2

The circuit diagram of state 2 is shown in Fig $2 b$. The active switch $\mathrm{S}$ is turned off. As the magnetic fluxes have to be steady, two new current loops start to function. The current through the storage inductor $L$ closes via capacitor $C$ and the diodes $D_{1}$ and $D_{2}$ (short dash line). The magnetizing current commutates from winding $N_{1}$ into winding $N_{2}$ and closes via capacitor $C$ and the diode $D_{2}$ (dotted line). The value of the magnetizing current in $N_{2}$ jumps at this moment to

$$
i_{N 2}=\frac{N_{1}}{N_{2}} \frac{V_{1}}{L_{1}} t_{1}
$$

and increases according

$$
\frac{d i_{N 2}}{d t}=-\frac{V_{2}}{L_{1}} \cdot\left(\frac{N_{1}}{N_{2}}\right)^{2}
$$

until the current reaches zero and the transformer is demagnetized (cf. Fig. 3b). As in state 1 the load is parallel to the capacitor $C$ (long dashed line). To avoid the loss caused by the series connection of the two diodes, a third diode in forward direction between the anode of the second diode $D_{2}$ and the cathode of the first diode $D_{1}$ has to be connected.

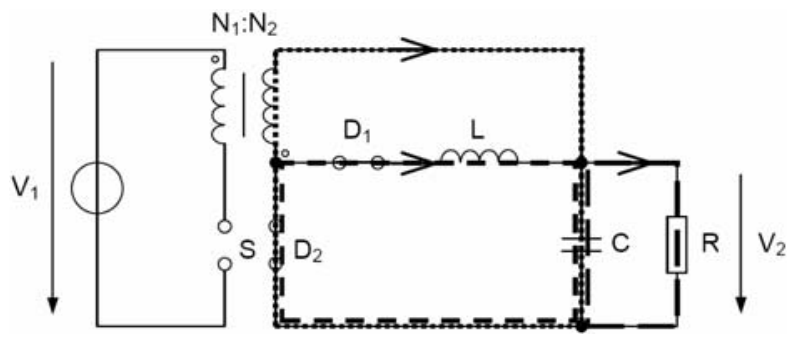

Fig. $2 b$ State 2 of the combined forward-flyback converter

\section{State 3}

The circuit diagram of state 3 is shown in Fig. 2c. Both the transformer and the storage inductor are demagnetized. The load is supplied by capacitor $C$ (long dashed line). Stage three ends when $S$ is turned on again. The circuit is now in state 1 again.

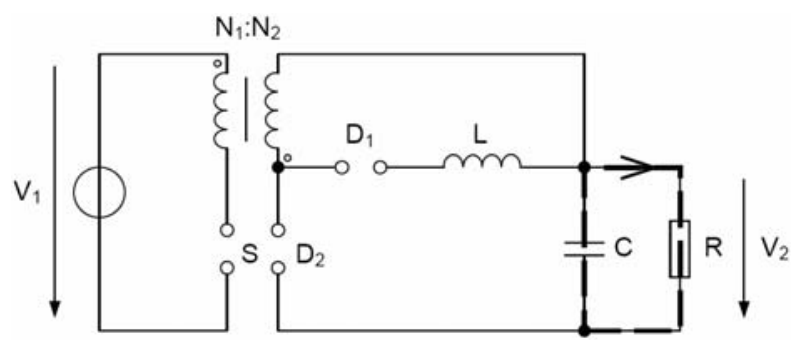

Fig. 2c State 3 of the combined forward-flyback converter

\section{Voltage Transfer Rate}

A. Combined forward-flyback converter
To calculate the voltage transfer rate of the combined forwardflyback converter, the assumption is used that the output power must be the same as the input power when ideal components are used

$$
P_{\text {out }}=\frac{V_{2}^{2}}{R}=P_{m} .
$$

The current in the inductor $L$ (Fig. 3.a) rises during the ontime of the switch $S$ according to

$$
\Delta I_{L}=\frac{V_{1}}{L} \cdot \frac{N_{2}}{N_{1}} \cdot d \cdot T
$$

and leads to a stored energy at the end of the on-time of the active switch of

$$
W_{L}=\frac{\Delta I_{L}^{2}}{2} \cdot L .
$$

The magnetizing energy of the transformer increases with the magnetizing current, which reaches

$$
\Delta I_{m}=\frac{V_{1}}{L_{1}} \cdot d \cdot T
$$

at the end of the turn-on time of the active switch leading to

$$
W_{m}=\frac{\Delta I_{m}^{2}}{2} \cdot L_{1} .
$$

During the off-time of the active switch this energy has to be decreased to zero, so that both inductive components are demagnetized again. Within one second the absorbed power of the converter is

$$
\frac{V_{2}^{2}}{R}=f \cdot\left(W_{L}+W_{m}\right) .
$$

The output voltage can now be calculated according to

$$
V_{2}=\sqrt{R} \cdot \frac{V_{1} \cdot d}{\sqrt{2 \cdot f}} \cdot \sqrt{\left(\frac{N_{2}}{N_{1}}\right)^{2} \cdot \frac{1}{L}+\frac{1}{L_{1}}}=K_{C} \cdot \sqrt{R} \cdot V_{1}
$$

with $K_{C}$ as a constant consisting of the converter parameters inductor $L$, magnetizing (primary) inductance $L_{1}$, winding ratio $N_{2} / N_{1}$, and switching frequency $f$.

To compare the combined converter with the conventional forward and the conventional flyback converter, we have to calculate the output voltage in the discontinuous mode. The discontinues mode is necessary to demagnetize the inductive devices completely.

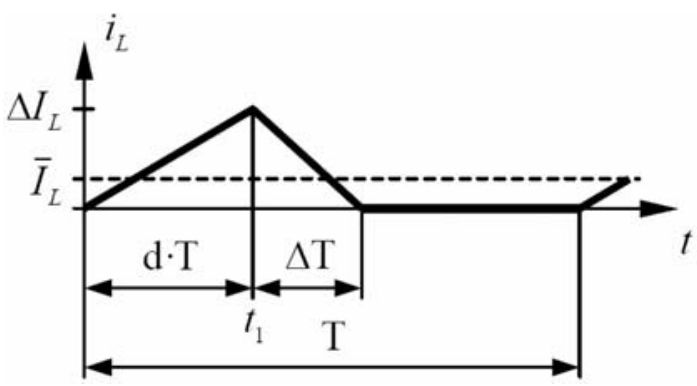

Fig. 3a Current through the inductor $L$ 
The transformer has to be demagnetized before the active switch is turned on again.

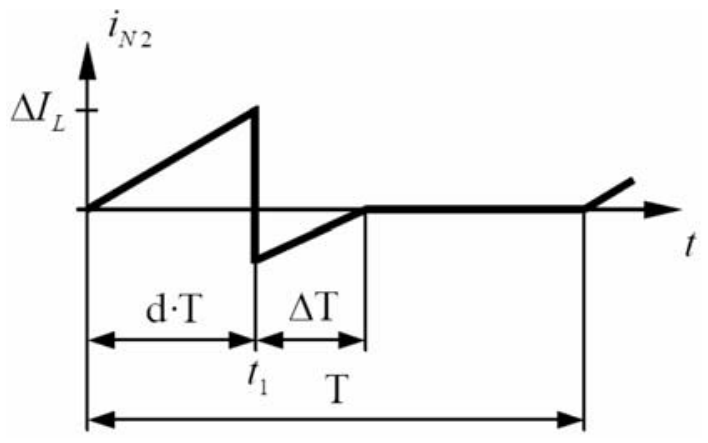

Fig. $3 b$ Current through the secondary winding $\mathrm{N}_{2}$

Duty cycle requirement

The converter has to be operated in the discontinuous mode The maximum current through the inductor is

$$
\Delta I_{L}=V_{1} \cdot \frac{N_{2}}{N_{1}} \cdot \frac{d \cdot T}{L}
$$

and the time that is needed for demagnetizing this coil is

$$
T_{D L}=\frac{L \cdot \Delta I_{L}}{V_{2}}=d \cdot T \cdot \frac{V_{1}}{V_{2}} \cdot \frac{N_{2}}{N_{1}} .
$$

It must be valid

$$
d \cdot T+T_{D L}<T
$$

and therefore we get the constraint

$$
d \cdot\left(1+\frac{V_{1}}{V_{2}} \frac{N_{2}}{N_{1}}\right)<1 .
$$

The transformer has to be demagnetized completely. The maximum magnetizing current (8) on the primary side has to be converted by the winding ratio to the secondary side. The necessary demagnetization time of the converter is now

$$
T_{D T}=\frac{V_{1}}{V_{2}} \cdot d \cdot T \cdot \frac{N_{2}}{N_{1}} .
$$

It must be valid

$$
d \cdot T+T_{D T}<T
$$

and therefore we get again the constraint

$$
d \cdot\left(1+\frac{V_{1}}{V_{2}} \frac{N_{2}}{N_{1}}\right)<1 .
$$

The demagnetizing time is the same for the inductor and the transformer.

With (11) and (18) we can write

$$
d<1-\frac{N_{2}}{N_{1}} \cdot \frac{1}{K_{C} \cdot \sqrt{R}}
$$

with converter coefficient

$$
K_{C}=\sqrt{\left[\left(\frac{N_{2}}{N_{1}}\right)^{2} \cdot \frac{1}{L}+\frac{1}{L_{1}}\right] \cdot \frac{1}{2 \cdot f}} .
$$

\section{B. Forward converter}

To calculate the output voltage of the forward converter (Fig. 4), only the energy in the inductor has to be taken into consideration, the magnetizing energy of the transformer is fed-back to the input voltage source via the additional winding $N_{3}$. The maximum stored energy depends on the maximum inductor current which is reached at the end of the on-interval of the active switch

$$
\Delta I_{L}=\left(\frac{N_{2}}{N_{1}} \cdot V_{1}-V_{2}\right) \cdot \frac{1}{L} \cdot d \cdot T
$$

Within the time

$$
\Delta T=L \cdot \Delta I_{L} \cdot \frac{1}{V_{2}}=\left(\frac{N_{2}}{N_{1}} \cdot V_{1}-V_{2}\right) \cdot \frac{d \cdot T}{V_{2}}
$$

the inductor is discharged. The mean value of the inductor current must be the same as the load current.

The input power of the converter is the input voltage multiplied by the mean value of the input current. The input current is triangular in shape. The input power is therefore

$$
P_{i n}=V_{1} \cdot \frac{1}{T} \cdot \frac{1}{2} \cdot \frac{N_{2}}{N_{1}} \cdot\left(\frac{N_{2}}{N_{1}} \cdot V_{1}-V_{2}\right) \cdot \frac{1}{L} \cdot d^{2} \cdot T^{2}
$$

and this must be equal to the output power

$$
P_{\text {out }}=\frac{V_{2}^{2}}{R}=V_{1} \cdot \bar{I}_{1}=P_{\text {in }} .
$$

The output voltage of the forward converter in discontinuous mode can now be evaluated according to

$$
V_{2}=\frac{N_{2}}{N_{1}} \cdot \frac{R \cdot V_{1} \cdot d^{2}}{4 \cdot L \cdot f} \cdot\left(-1+\sqrt{1+\frac{8 \cdot L \cdot f}{R \cdot d^{2}}}\right) .
$$

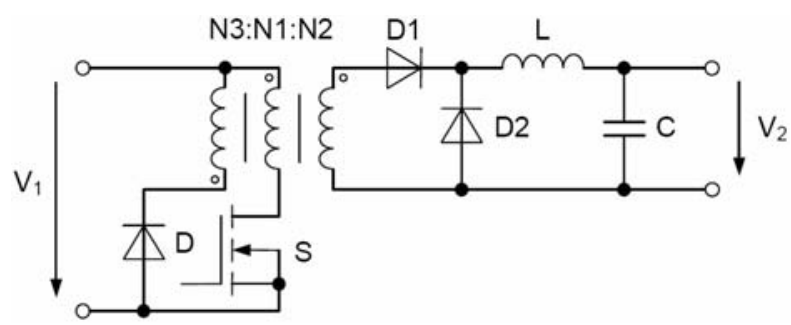

Fig. 4 Circuit of the classical forward converter

\section{Flyback converter}

The circuit diagram of the flyback converter is shown in Fig 5. Under the assumption of ideal components the output power must be the same as the input power 


$$
P_{\text {out }}=\frac{V_{2}^{2}}{R}=P_{\text {in }} .
$$

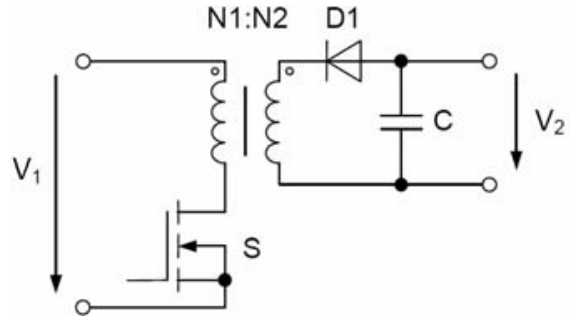

Fig. 5 Circuit of the classical flyback converter

The magnetizing energy of the transformer increases with the magnetizing current, which reaches

$$
\Delta I_{m}=\frac{V_{1}}{L} \cdot d \cdot T
$$

at the end of the turn-on time of the active switch leading to.

$$
\begin{aligned}
& W_{m}=\frac{\Delta I_{m}^{2}}{2} \cdot L_{1} \\
& \frac{V_{2}^{2}}{R}=f \cdot W_{m} .
\end{aligned}
$$

The output voltage can now be calculated according to

$$
V_{2}=\sqrt{\frac{1}{2 \cdot f \cdot L_{1}}} \cdot \sqrt{R} \cdot V_{1} \cdot d=K_{F} \cdot \sqrt{R} \cdot V_{1} \cdot d,
$$

with $K_{F}$ as a constant consisting of the magnetizing inductance $L_{1}$, and the switching frequency $f$.

\section{Theoretical Results}

The voltage transfer ratio of the three converters is compared for the same different load resistances, constant input voltage, and the same component values for all three topologies $L_{1}=L_{3}=$ $=300 \mu \mathrm{H}, L_{2}=75 \mu \mathrm{H}, L=50 \mu \mathrm{H}$.

The scales are the same for all diagrams. Fig. 6a shows the voltage transfer ratio of the combined forward-flyback converter and Figs. $6 \mathrm{~b}$ and $6 \mathrm{c}$ show the voltage transfer rate for the forward and the flyback converter, respectively. The voltage transfer ratio of the new converter is significantly higher compared to the forward and the flyback converters.

\section{Statespace Description of the Combined Converter}

The state variables are the flux $\phi$ of the transformer, the inductor current $i_{L}$, and the capacitor voltage $u_{C}$. The input variable is the input voltage $u_{1}$. The fixed forward voltage of the diodes (the

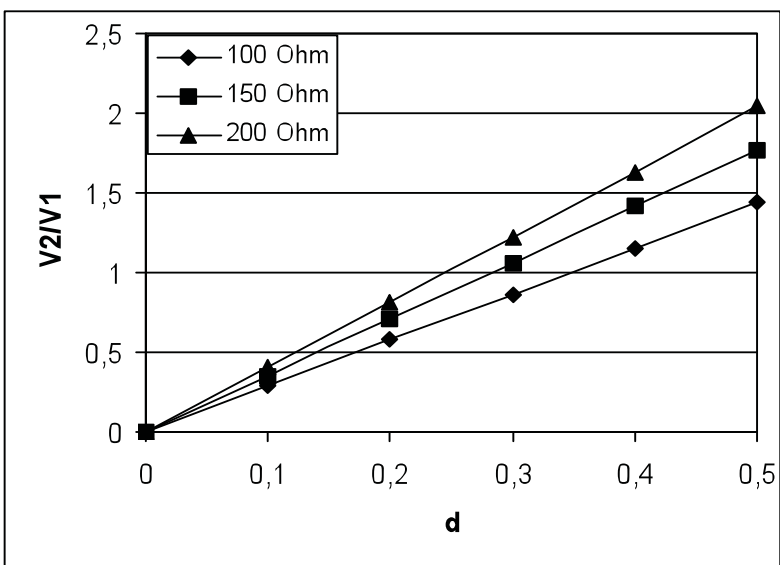

Fig. 6 a Voltage transfer ratio of the combined forward-flyback converter

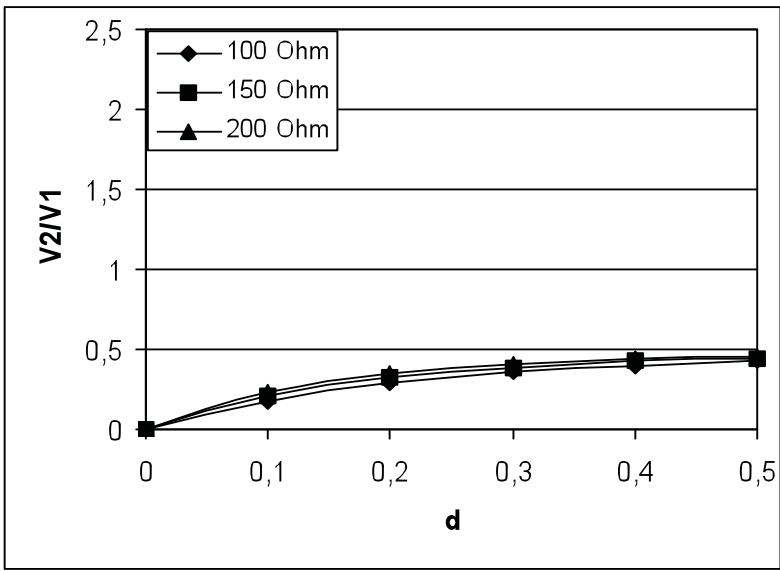

Fig. $6 b$ Voltage transfer ratio of the classical forward converter

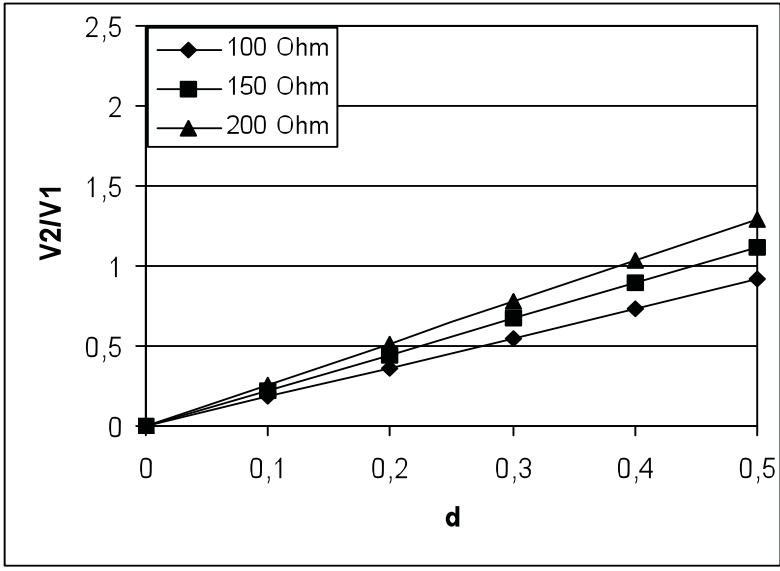

Fig. 6c Voltage transfer ratio of the classical flyback converter

diodes are modeled as fixed forward voltages $V_{D 1}, V_{D 2}$ and additional voltage drops depending on the differential resistors of the diodes $R_{D 1}, R_{D 2}$ ) are included as additional vectors. The parasitic 
resistances are the on-resistance of the active switch $R_{S}$, the series resistance of the coil $R_{L}$, the series resistor of the capacitor $R_{C}$, and the differential resistors of the diodes $R_{D 1}, R_{D 2}$. With the $A_{L}$ value of the transformer material the primary inductor is $L_{1}=$ $=A_{L} \cdot N_{1}^{2}$ and the secondary inductor is $L_{2}=A_{L} \cdot N_{2}^{2}$. The abbreviation $R_{C} / / R$ describes the parallel connection of the serial resistor of the output capacitor and the load resistor.

In discontinuous inductor current mode there are three states. In state one the active switch is turned on and also the passive switch $D_{1}$ turns on. Fig. 7a shows this switching state one. There are other possibilities to analyze circuits with different methods like shown e.g. in [14]. This would be especially useful for calculating the spectrum for EMC analyses. The leakage inductor is not included. (The leakage inductor is small because of the bifilar winding and leads in practice to small reduction of the input voltage. The energy which is stored must be transformed into heat by a snubber circuit when the overvoltage across the active switch is too high.) The complete flux which is connected with the winding is $\psi=N \cdot \phi$.

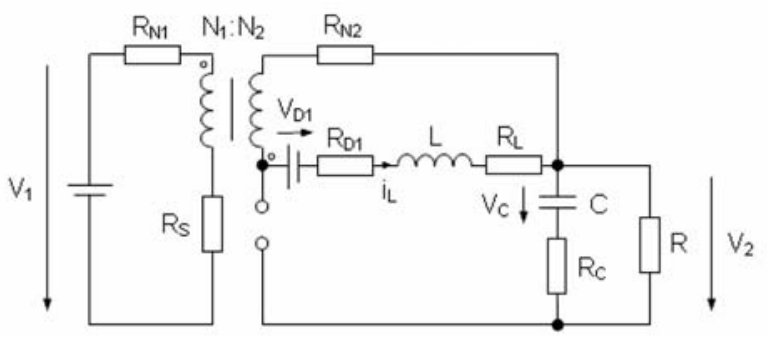

Fig. 7a Equivalent circuit for stage one

The state space description is

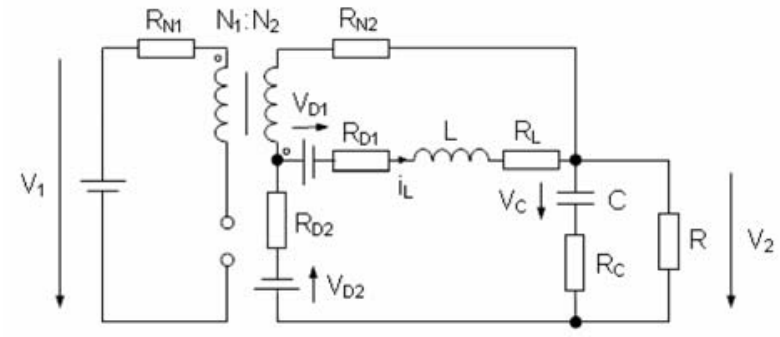

Fig. $7 b$ Equivalent circuit for stage two

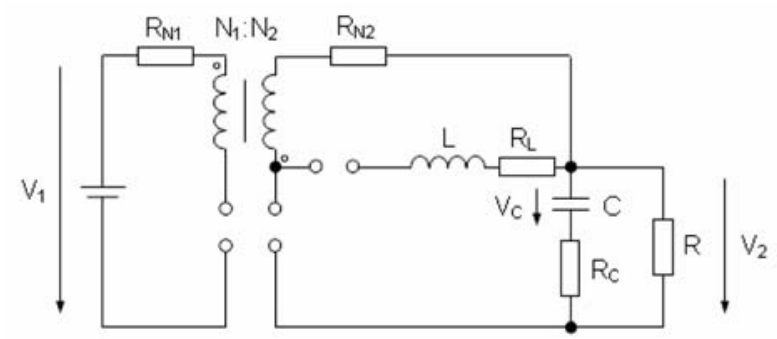

Fig. 7c Equivalent circuit for stage three

When the transformer and the coil are demagnetized the load current discharges the capacitor. Fig. 7c shows this switching state three. The change of the capacitor voltage is now

$$
\frac{d}{d t} v_{C}=-\frac{v_{C}}{C\left(R+R_{C}\right)}
$$

$$
\frac{d}{d t}\left(\begin{array}{c}
\phi \\
i_{L} \\
v_{C}
\end{array}\right)=\left[\begin{array}{ccc}
-\frac{R_{N 1}+R_{S}}{L_{1}} & 0 & 0 \\
-\frac{N_{2}}{L}\left(\frac{R_{N 1}+R_{S}}{L_{1}}+\frac{R_{N 2}}{L_{2}}\right)-\frac{R_{D 1}+R_{L}}{L} & 0 \\
0 & 0 & -\frac{1}{C\left(R+R_{C}\right)}
\end{array}\right] \cdot\left(\begin{array}{c}
\phi \\
i_{L} \\
v_{C}
\end{array}\right)+\left[\begin{array}{c}
\frac{1}{N_{1}} \\
\frac{1}{L} \\
0
\end{array}\right] \cdot v_{1}\left(\begin{array}{c}
0 \\
-\frac{1}{L} \\
0
\end{array}\right) \cdot V_{D 1}
$$

In state two the active switch $S$ is turned off, the passive switch $D_{1}$ is still conducting, and the second passive switch $D_{2}$ turns on. Fig. $7 \mathrm{~b}$ shows this switching state two. The state space description is

$$
\frac{d}{d t}\left(\begin{array}{c}
\phi \\
i_{L} \\
v_{C}
\end{array}\right)=\left[\begin{array}{ccc}
-\frac{R_{C} / / R+R_{D 2}+R_{N 2}}{L_{2}} & -\frac{R_{C} / / R+R_{D 2}}{N_{2}} & -\frac{R}{N_{2}\left(R+R_{C}\right)} \\
-\frac{R_{C} / / R+R_{D 2}}{L \cdot L_{2}} & -\frac{R_{C} / / R+R_{D 1}+R_{D 2}+R_{L}}{L} & -\frac{R}{L\left(R+R_{C}\right)} \\
\frac{R}{C\left(R+R_{C}\right)} & \frac{N_{2} R}{C L_{2}\left(R+R_{C}\right)} & -\frac{1}{C\left(R+R_{C}\right)}
\end{array}\right] \cdot\left(\begin{array}{l}
\phi \\
i_{L} \\
v_{C}
\end{array}\right)+\left[\begin{array}{c}
0 \\
1 \\
L \\
0
\end{array}\right] \cdot V_{D 1}\left(\begin{array}{c}
-\frac{1}{N_{2}} \\
0 \\
0
\end{array}\right) \cdot V_{D 2}
$$

\section{Measurement Results}

Now some experimental results of the new converter topology will be shown. In Fig. 8 the voltage across the active switch $(\mathrm{Ch} 2$ : 
$20 \mathrm{~V} /$ div) and the current through the inductor (Ch1: 2 A/Div) can be seen. The results follow as predicted.

For more convenient measuring, a two-diode-combined-forwardflyback converter with a tapped inductor (autotransformer) was built (Fig. 9). The winding ratio is one to one and the windings are bifilar. The inductor $\mathrm{L}$ was realized with an isolated stranded wire and with a gapped core. No snubber was necessary because of the low leakage inductance of the autotransformer. The converter was used with open loop control.

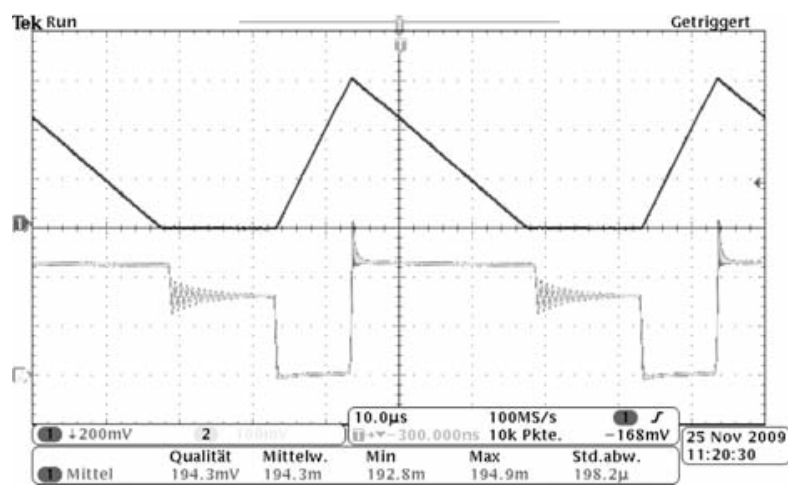

Fig. 8 Current through the inductor (Ch1: 2 A/Div) and voltage across the active switch (Ch2: $20 \mathrm{~V} /$ div)

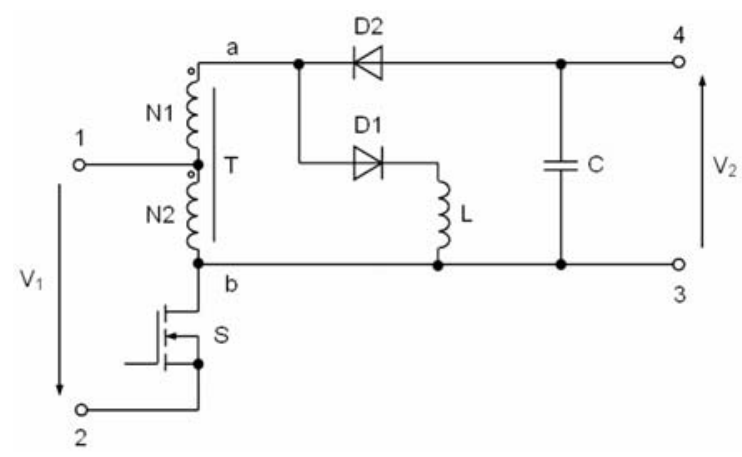

Fig. 9 Autotransformer two-diode-combined-forward-flyback converter

Figs. 10 and 11 show (up to down) the voltage across the active switch, the current through the inductor, and the current through the winding $N_{1}$; the input voltage is $24 \mathrm{~V}$, the load is 11 $\mathrm{Ohm}$ and the duty cycle is $16 \%$ and $45 \%$ respectively. The output voltage is $14 \mathrm{~V}$ with the small duty cycle, and $38 \mathrm{~V}$ with the higher one.

The most interesting signal is the current through the autotransformer winding $N_{1}$. During the on-time of the active switch, the current is the same as the one in the filter inductor. When the transistor turns off, the current of the inductor is freewheeling, and through $N_{1}$ now flows the magnetizing current of the autotransformer.

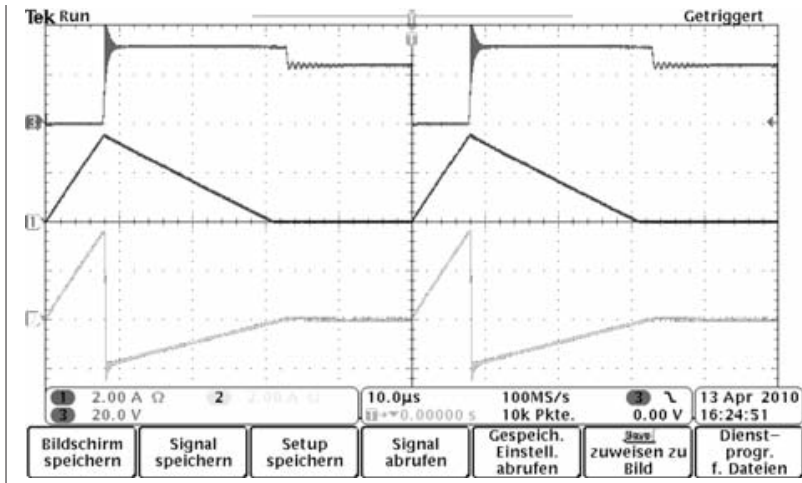

Fig. 10 Voltage across the active switch (Ch3: $20 \mathrm{~V} /$ div), current through the inductor (Ch1: $2 \mathrm{~A} / \mathrm{Div}$ ), and current through the winding N1 (Ch2: 2 A/Div); input voltage $24 \mathrm{~V}$, duty cycle 16\%, output voltage $14 \mathrm{~V}$, load $11 \mathrm{Ohm}$.

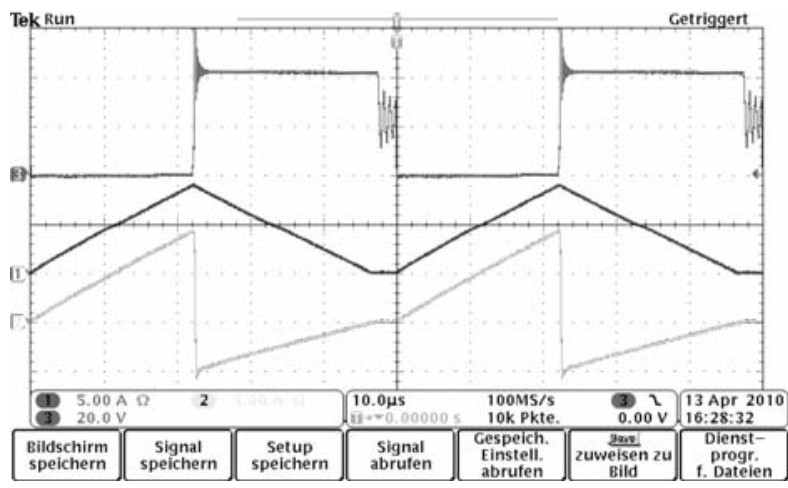

Fig. 11 Voltage across the active switch (Ch3: $20 \mathrm{~V} /$ div), current through the inductor (Ch1: $5 \mathrm{~A} / \mathrm{Div}$ ), and current through the winding N1 (Ch2: 5 A/Div); input voltage $24 \mathrm{~V}$, duty cycle 45\%, output voltage $38 \mathrm{~V}$, load $11 \mathrm{Ohm}$.

\section{Conclusion}

The combined forward-flyback converter with two diodes has three interesting aspects. Due to the fact that the voltage across the secondary winding $N_{2}$ and across the inductor $\mathrm{L}$ is the same, the converter must be used in the discontinuous mode. The transformer has to be demagnetized before the active switch is turned on again. This has the advantage that from the control point of view the converter is only a first order system, as all magnetic elements have no energy at the beginning of all switching periods. All diodes turn off naturally, no forced commutation occurs and this leads to reduced switching losses and a better efficiency. For the same values of the components more power can be transformed compared to the forward and flyback converter. A higher output voltage can be achieved by the same duty ratio compared to the forward and flyback converter. The converter is useful for applications where a flyback converter is too small (flyback converters have the disadvantage that for higher power ranges a big trans- 
former has to be used) and a forward converter with its complicated transformer is too expensive. By shunting the two diodes by a third one, the efficiency can be increased and due to the reduced losses the cooling is easier. The converter is especially useful for renewable energy applications and for compact systems.

\section{Acknowledgment}

The authors are very grateful to the city council of Vienna which supports the Technikum Wien with new measurement equipment by the project MA 27-Projekt 09-32.

\section{References}

[1] MOHAN, N., UNDELAND, T., ROBBINS, W. P.: Power Electronics. John Wiley \& Sons, New York, 2003.

[2] ZACH, F.: Leistungselektronik. Springer, Wien, 2010.

[3] ERICKSON, R. W., MAKSIMOVIC, D.: Fundamentals of Power Electronics. Springer Science+Business Media, Inc., New York, 2001.

[4] BOSE, B.: Power Electronics and Motor Drives. Elsevier Academic Press, 2006.

[5] KAZMIERKOWSKI, M. P.: Control in Power Electronics. Selected Problems. Academic Press Series in Engineering, 2002.

[6] HIMMELSTOSS, F., HOFFELNER, A., VOTZI, H.: Kombinierter Sperr-Durchflusswandler. Austrian Patent AT 506327 B1, Aug. 2009.

[7] CHANGCHIEN, S.K., LIANG, T.J., TSENG, K.C., CHEN, J.F., LIN, R.L.: A Demagnetization Circuit for Single-ended Forward Converter. IEEE IECON. pp. 1390-1395, 2007.

[8] JIN, T., ZHANG, K., AZZOLINI, A., SMEDLEY, K.M.: A New Interleaved Forward Converter with Inherent Demagnetizing Feature. IEEE IAS. Vol. 1, pp.625-630, 2005.

[9] FARCAS, C., PETREUS, D., SIMION, E., PAlAGHITA, N., JIHOS, Z.: A Novel Topology Based on Forward Converter with Passive Power Factor Correction. ISSE. pp. 268-272, Oct. 2006.

[10] GALLO, C.A.,TOFOLI, F.L.,SCARPA, V.V.R., DE FREITAS, E.A.A., VIEIRA, J.B. Jr.: Proposal of a SMPS with AC Output Voltage Employing a Quadratic Boost Converter, a new Topology of Soft-switched Two-switch Forward Converter and a New Topology of PWM Three-level Half-bridge Inverter. IEEE PESC, Vol. 4, pp. 2604-2610, June, 2004.

[11] ZHANG, M.T., JOVANOVIC, M.M., LEE, F.C.: Analysis, Design, and Evaluation of Forward Converter with Distributed Magnetics-interleaving and Transformer Paralleling. APEC, Vol. 1, pp. 315-321, March, 1995.

[12] BRIDGE. C.D.: Clamp Voltage Analysis for RCD Forward Converters. IEEE APEC, Vol. 2, pp. 959-965, Feb. 2000.

[13] HIMMELSTOSS, F.A., VOTZI, H.L.: Comparison of a New Combined Four-diode Forward-flyback Converter with the Classical Forward Converter. IEEE ISSCS, pp. 493-496, July 2009.

[14] ZASKALICKA, M., ZASKALICKY, P., BENOVA, M., ABDALMULA, M.A.R., DOBRUCKY, B.:Analysis of Complex Time Functions of Converter Output Quantities Using Complex Fourier Transform/Series, Communications - Scientific Letters of the University of Zilina, No. 1, pp. 23-30, 2010. 